\title{
A Parisian museum to be defended
}

Museums are not the same as galleries, and should not become so. The Musée de l'Homme in Paris presents an excellent opportunity publicly to bring together disciplines that were until recently estranged.

IF one agrees with Alexander Pope that the proper study of mankind is man, one should welcome the overhaul of the Musée de l'Homme in Paris as an excellent opportunity to draw together the increasingly disparate strands of research on human beings, and present them to the public, under one roof. Unfortunately, the conflicting temptation (see page 109) to reinvent the museum as a gallery of primitive art also has its attractions (not least financial). To see the scale of the opportunity that would thus be lost, one needs to examine why museums and galleries are different things, and how they have become increasingly so over the past few years.

The essence of a gallery is its provision of space wherein one contemplates objects - usually art - that exist either for their own sake or as representations of aesthetic values more or less remote from scholarship. Many of the objects now housed in the Musée de l'Homme, or in the Paris Museum of African and Oceanic Arts (whose collections are planned to be merged with those of the Musée de l'Homme), are beautiful in themselves. But to display them simply as objets d'art would be to miss the chance to exploit their other function, that of the product of a culture and technology the interest of which is greater than the object itself.

There is another danger. The display of artefacts for their own sake is increasingly seen as patronizing. Curators of ethnographic collections face increasing demands from native peoples for the repatriation of objects of ritual significance. Unless one can show that the inclusion of such things in a museum display is in the context of educational purposes, such demands seem justified. In that case, a display of ethnic objects for their own sake is not only outmoded, but is a kind of cross-cultural voyeurism.

Thankfully, museums have moved on from being just galleries - as too many used to be. It is now rare for their displays to consist of obscurely labelled curiosities, exhibited without context. The need to provide the visitor with some idea about specimens' origins and functions is one of the motivations behind the wave of renovations now sweeping the world's museums. The other, of course, is financial. Museums must attract paying customers in order to remain viable: these days, they are in the leisure business, competing with theme parks, cinemas and other manifestations of popular culture.

The best displays now combine superb specimens with attractive design, interactive technology, graphics and text, leading the visitor on a preplanned course through the subject. The new Earth Galleries at the Natural History Museum in London provide one instance: where once there were racks of rocks, each labelled with incomprehensible terminology in very small print, there is now a spectacle that entices one to explore the Earth's surface and interior. The revamped fossil halls at the American Museum of Natural History in New York provide another example. There, fossils are arranged along a phylogenetic theme, and the visitor is drawn along the family tree of the vertebrates. Specimens are splendidly displayed - and, as it happens, in a way that reflects the research strengths of the museum.

High on the agenda of the projected restoration in Paris should be the reunion (after a long and unhappy separation) of evolution and anthropology. In the 1960s, many anthropologists shied away from evolution for fear of being branded racist. Their discipline was thus denied access to a vital perspective of its main substrate, human diversity.

That tide is turning, and the Musée de l'Homme would be well placed to benefit. It would be the ideal forum in which to present recent results from the Human Genome Project, the initiatives to appreciate human genetic diversity, the connections between ethnic, cultural and linguistic diversity, the pressures of population on the environment, the contributions of ethnobotany and folk medicine to modern pharmacology, the latest fossil finds, and much more besides. Art objects too have their place within such a scheme, but as specimens to punctuate a connected narrative display, not just as ends in themselves.

\section{Moving targets}

Migrant researchers with a shadowed past are a growing problem for research institutions.

SCIENTIFIC fraud and malpractice can be a traumatic experience for all involved. This is most obvious for those whose scientific and personal judgement has been exposed to harsh scrutiny, whether in public or in private. But it also applies to others who may have been involved in establishing whether or not a deliberate act of falsification or deception has taken place - a procedure with which those trained in legal rather than academic disciplines are inevitably more comfortable. Understandably, the individuals and institutions alike may seek to minimize both discomfort and risks by keeping quiet.

What happens when a researcher over whom some professional shadow has fallen wishes to move elsewhere? The employers-to-be have their own need to know the background, yet it is of primary importance that the interests of those accused of scientific misbehaviour receive adequate protection. Reckless charges of misconduct can wreck a promising career, and may be prompted by professional jealousies.

Nevertheless, well-founded doubts about individuals should be passed in confidence from one institution to another. Yet obstacles can arise, particularly at the international level, where information flow is often reduced to formal communication, geographical distance may reduce a sense of mutual responsibility, informal contact is at a minimum - if it exists at all - and fears of expensive and time-consuming litigation can dominate all other considerations.

Unfortunately, such cases may now be affecting an increasing number of the world's major research institutions (see pages 107-108). In response, it is tempting to dream up some institutionalized means of addressing the problem. Learned societies and academies might wish to collaborate in examining the issue, but the practical and legal difficulties confronting any formal procedures would be severe, to put it mildly. Those seeking to employ researchers from overseas have no alternative but to bear this phenomenon in mind when, ever more carefully, they seek information regarding a candidate's suitability. 